\title{
NEUROSURGICAL METHODS IN THE TREATMENT OF TUBERCULOUS MENINGITIS \\ WITH A NOTE ON SOME UNUSUAL MANIFESTATIONS OF THE DISEASE
}

\author{
BY \\ SIR HUGH CAIRNS \\ From the Radcliffe Infirmary, Oxford
}

The place of neurosurgical methods in the management of tuberculous meningitis has not yet been clearly defined. In Oxford, since our first therapeutic intrathecal trials of penicillin in 1943, neurosurgical methods have been freely used in many varieties of meningitis, and in this paper I shall describe them and try to assess their value in tuberculous meningitis. Under the term ' neurosurgical methods 'I include all operative procedures, such as cranial exploration by burr-holes or craniotomy, which are not normally employed by the physician.

\section{Ventricular Estimation and Ventriculography for Diagnosis}

In his Lectures on Diseases of Children, as pleasing and profitable to read now as they were 30 years ago, Sir Robert Hutchison indicates the difficulties which may be encountered in the diagnosis of tuberculous meningitis. He speaks of 'the extraordinary variability' of the course of the disease. And again, 'the more numerous the possible symptoms of any disease, the more difficult is it to diagnose that disease with certainty.' The diagnostic problem has become an urgent one since the introduction of streptomycin; and, as Goodhart and Still (1913) found, ' added experience only makes it clear . . . how treacherous is the disease, and how impossible in some cases it is to avoid mistakes.'

Lumbar puncture and careful search of the cerebrospinal fluid for acid-fast bacilli will establish the diagnosis in many cases, but neurosurgical methods become urgently necessary when, in a case in which there is some pleocytosis and rise of protein in the cerebrospinal fluid but tubercle bacilli have not yet been identified, there is doubt as to whether the underlying lesion is a pyogenic brain abscess with meningitis, or tuberculous meningitis. In the one case the abscess must be operated on with all speed if the patient is to survive; in the other case the need for intrathecal injections of streptomycin is equally urgent, even though the immediate danger to life is not so great.
The method is to explore both lateral ventricles through cranial burr-holes. When there is an abscess in one cerebral hemisphere the corresponding lateral ventricle tends to become obliterated and the ventricular system is displaced towards the opposite side. In meningitis, on the other hand, the lateral ventricles are symmetrically placed and equal in size; in tuberculous meningitis they are usually already slightly dilated by the time the patient is admitted to hospital, and from each of them 10 , 15 , or more ml. of cerebrospinal fluid can be obtained. Such a finding virtually excludes the presence of an abscess or massive tuberculoma in one cerebral hemisphere.*

This method of ventricular estimation is used almost daily in neurosurgical departments for many purposes besides those which we are now considering. It is carried out under local anaesthesia, and in expert hands its risks are no greater than those of cisternal puncture.

In the uncommon cases in which the results of ventricular estimation are equivocal, a small amount of air (10-20 ml.) may be injected to display the ventricles (Fig. 1). If there is an expanding lesion, such as an abscess, this procedure may be followed by a sharp reaction unless the lesion is promptly dealt with by operation; but in uncomplicated meningitis we have never seen any harm result from its use.

In tuberculous meningitis the ventricular cerebrospinal fluid may sometimes show tubercle bacilli when none has been found in the lumbar cerebrospinal fluid.

\section{Intraventricular Administration of Streptomycin for Spinal Block}

When spinal block develops, the ventricular route for giving streptomycin should be used without delay; in such circumstances continued use of the

* In exceptional cases the lateral ventricles do not become dilated at any stage of the meningitis, even though the subarachnoid pathways at the tentorial opening are obstructed. 


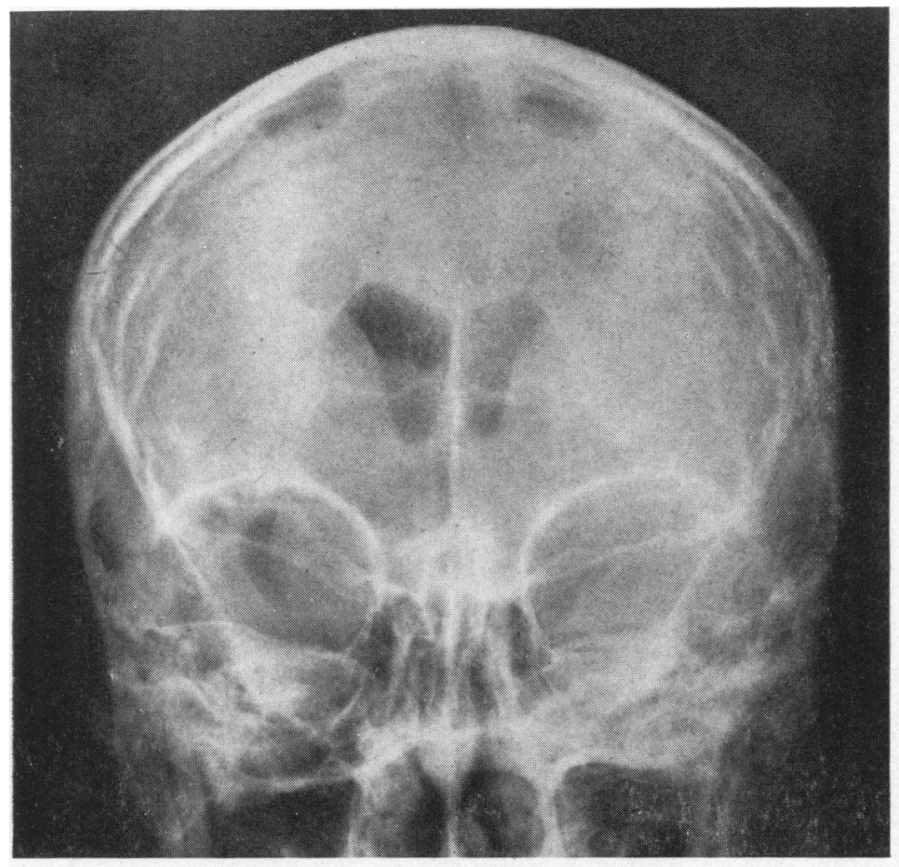

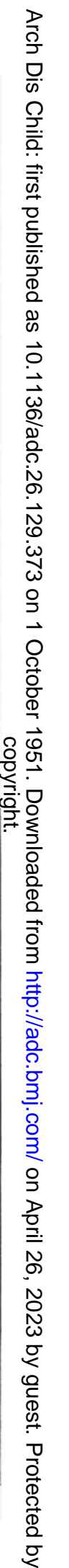

FIG. 1.-Air in the lateral and third ventricles following lumbar injection $(a)$ at the outset of treatment, $(b)$ two months later. E.C., a soldier aged 20 (69543, 1947), a case of miliary tuberculosis and tuberculous meningitis (Cairns and Taylor, 1949, Case 4).

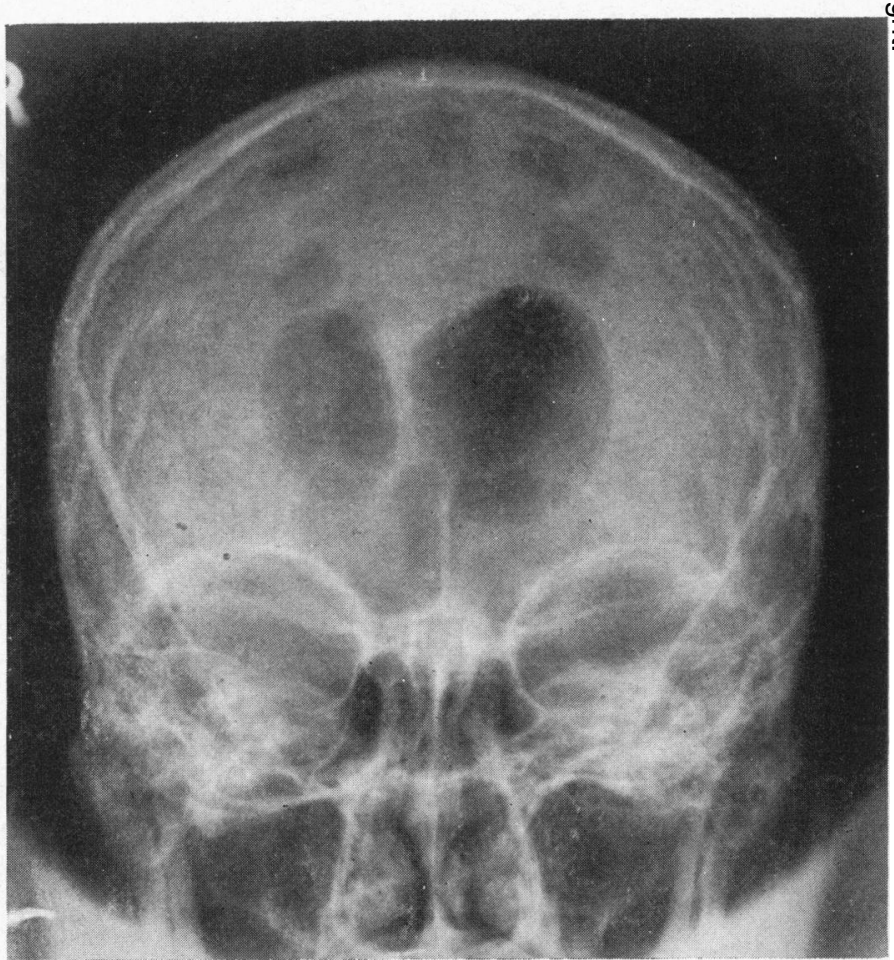

FIG. $1 b$ 


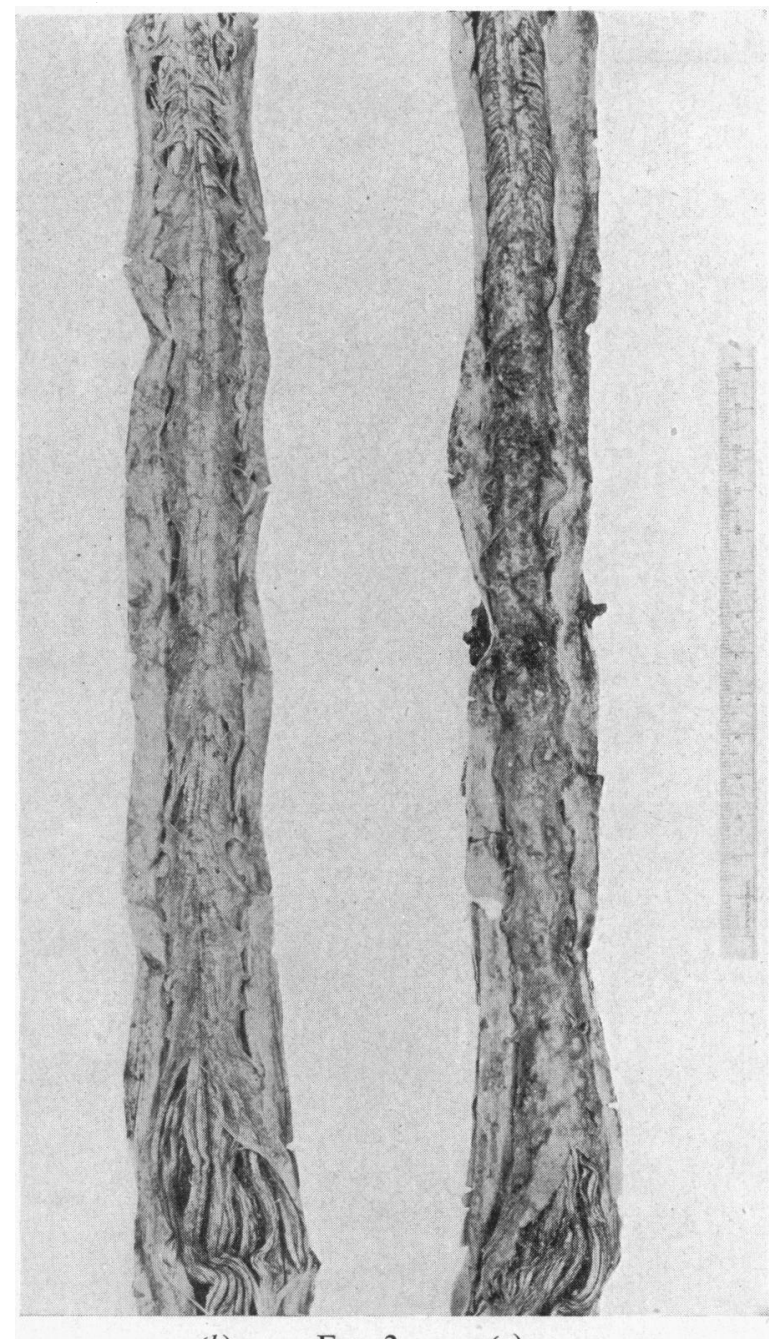

(b)
FIG. 2

(a)
Fig. 2.-Spinal exudate $(a)$ intense on the dorsal aspect, and $(b)$ mild on the ventral aspect of the spinal cord. M.E., aged 24 (64196, 1947), with chronic pulmonary tuberculosis and tuberculous meningitis complicated by pregnancy. Death in the fourth month of treatment.

FIG. 3.-Tracing of air blocked in the cisternae interpeduncularis and pontis after lumbar injection. Same case as Fig. 1.

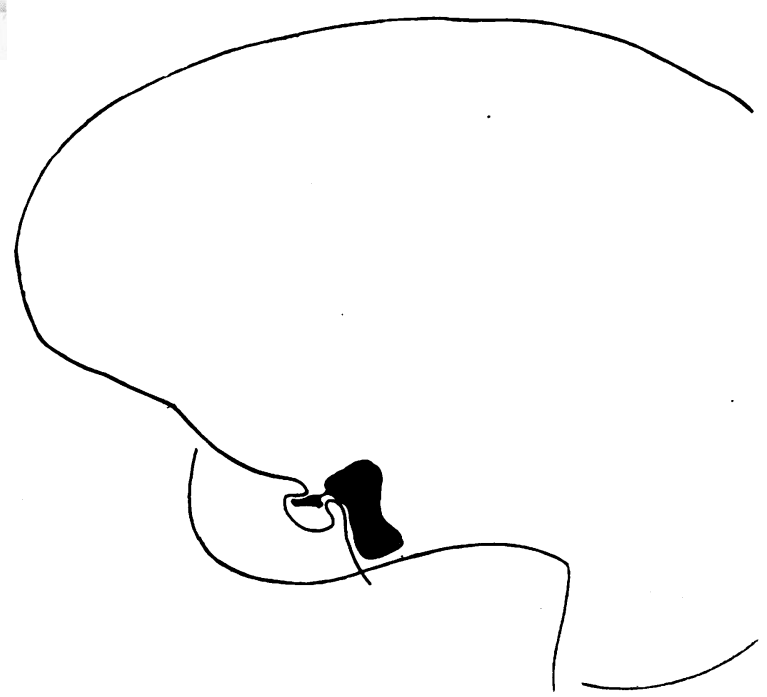

FIG. 3 
FIG. 4.-Chart of illness in a case of miliary and meningeal tuberculosis with a successful outcome. The intracranial pressure was at first high, but after ten days became and remained normal (F.K., aged 5, No. 105629, 1949).

FIG. 5.- The sagittal suture (a) on admission, and $(b)$ one year later. R.B., aged 11 years $(80497$, 1947). Primary lung complex and tuberculous meningitis.

Fig. 4

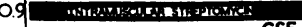

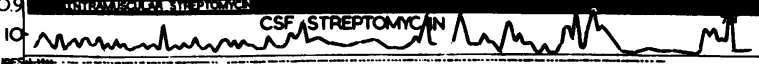
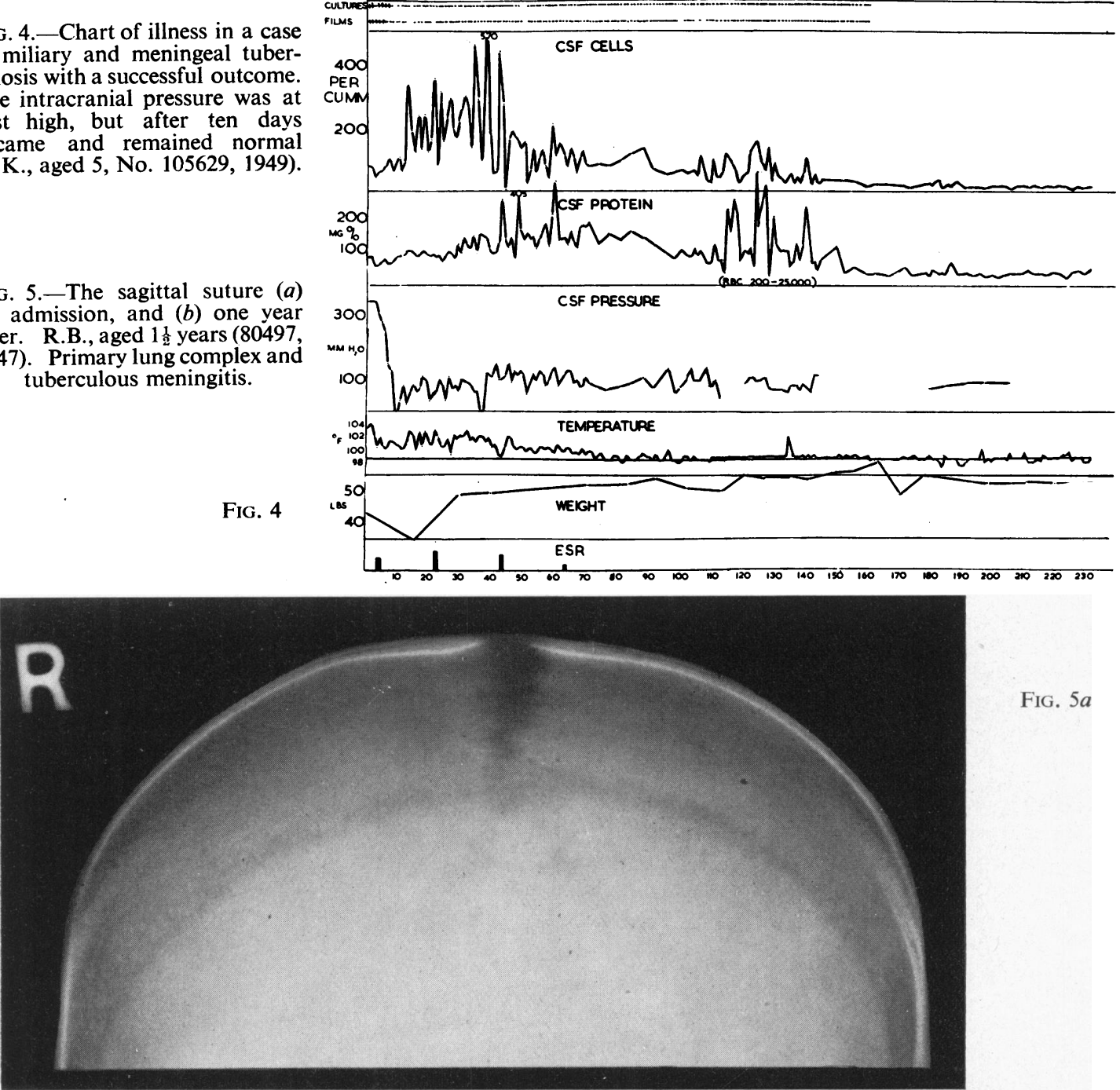

FIG. $5 a$

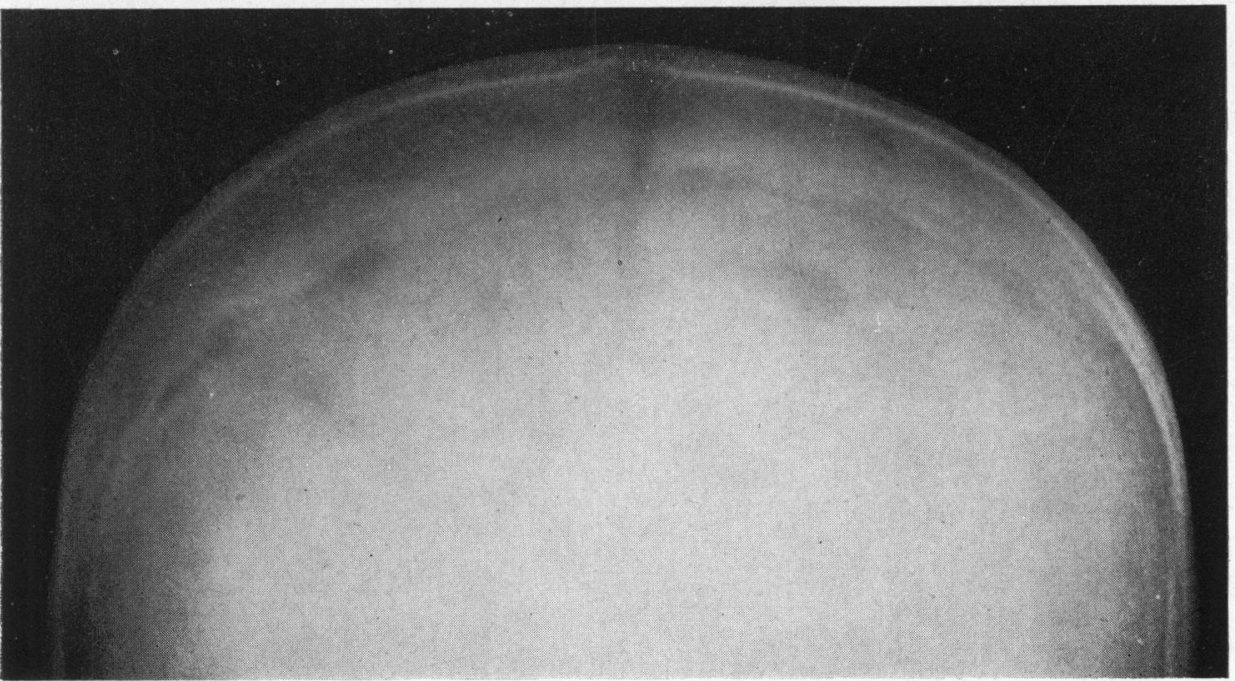

Fig. $5 b$ 
lumbar route for streptomycin injections is not only ineffective but may damage the cauda equina, with resultant paralysis of the legs and retention of urine. There should never be a day's intermission of the prescribed intrathecal course of streptomycin, and in practice it is best to make frontal burr-holes for access to the ventricles at the first suspicion of impending spinal block, if they have not already been made when the patient first comes under treatment.

Repeated use of the ventricular route carries the risk of cerebral haemorrhage and, in infants with greatly dilated ventricles, of cerebrospinal fluid leakage through the puncture hole. With reasonable care and skill these risks can be avoided. Dr. Raúl Carrea (1951), of Buenos Aires, has recommended an indwelling rubber catheter passing from the ventricle to the subgaleal space where it is punctured through the overlying scalp as required. This method should greatly reduce the risk of cerebral or ventricular haemorrhage.

The spinal theca became blocked at some stage during the course of streptomycin treatment in about one-third of our cases. I believe that we might be able to diminish the frequency of this awkward complication by measures to prevent the stagnation of cerebrospinal fluid. I have noticed in some cases at necropsy that the exudate in the spinal theca is profuse on the dorsal aspect of the spinal cord while the ventral aspect is relatively free (Fig. 2). This could be explained by continued dorsal decubitus, and suggests that the inert patient with meningitis should have very frequent changes of position, and that for parts of the day he should be nursed prone. Another method which we have used (Smith, Vollum, and Cairns, 1948; Cairns and Taylor, 1949) is the daily injection of $5 \mathrm{ml}$. of air into the subarachnoid space at the conclusion of the daily lumbar puncture. With the patient's head slightly raised, the air travels up the spinal theca and can subsequently be seen by radiographs in the cisterna interpeduncularis and Sylvian fissures (Fig. 3). These injections do not appear to be harmful, and if used regularly might diminish the liability to spinal block.

\section{Relief of Raised Intracranial Pressure}

In most cases of tuberculous meningitis there is at first a rise of intracranial pressure, as shown by the lumbar cerebrospinal fluid pressure (Fig. 4) and, in children, by radiographic demonstration of spreading of the sutures (Fig. 5). This rise of pressure is mainly due to obstruction of the subarachnoid space, especially in the cisternae interpeduncularis and ambiens which surround the brain stem at the tentorial opening. The cerebrospinal fluid must pass through this bottle-neck to be absorbed, and, when the cisterns are filled with tuberculous granulation tissue, hydrocephalus of the ' communicating' variety supervenes. Obstruction of the ventricular system, either at the aqueduct of Sylvius or at the foramen of Magendie (hydrocephalus of the 'obstructive' type) is rare. Proof of this statement is not limited to necropsy findings, for in life air injected into the lumbar subarachnoid space can be shown by x-ray examinations to pass easily into the ventricular system and the lower basal cisterns, but not into the Sylvian fissures and sulci of the cerebral convexity (Figs. 1 and 3 ). However, Lorber (1951) has-reported two-cases of obstruction of the aqueduct, and we have had one

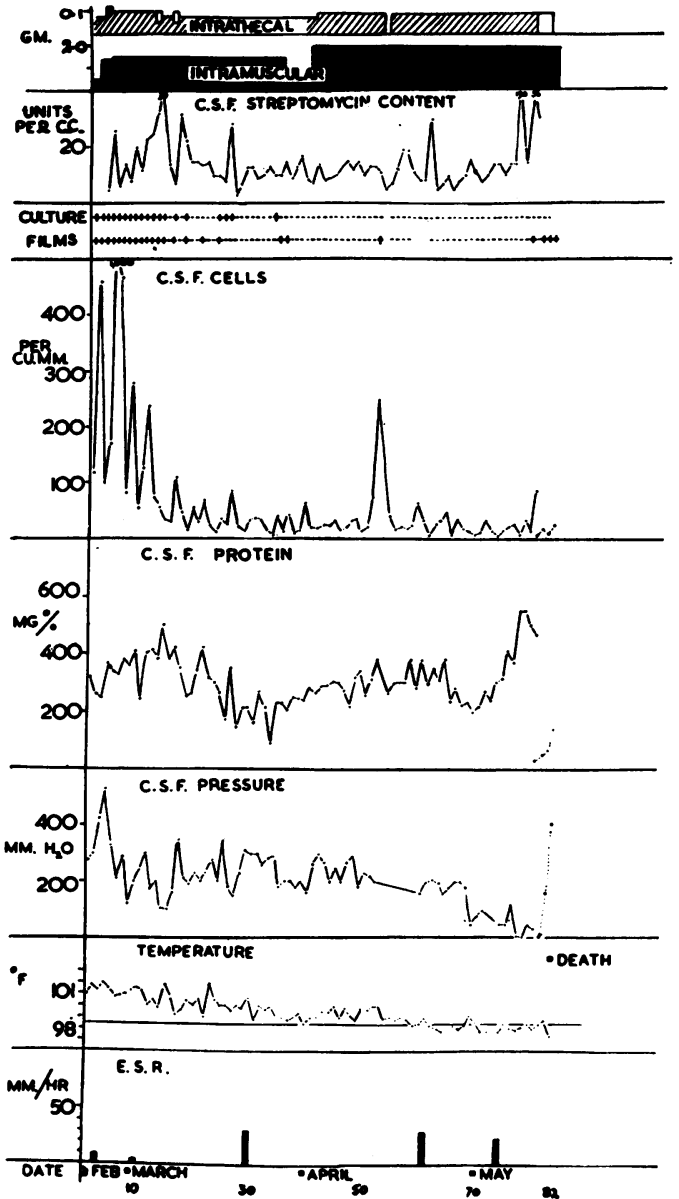

Fig. 6. - Chart of a fatal case of miliary and meningeal tuberculosis. The C.S.F. pressure fell to normal about the 70 th day of treatment, but rose 48 hours before death on the 82nd day. The terminal acute hydrocephalus coincided with the renewed appearance of acid-fast organisms in the C.S.F., indicating active disease. J.W., aged 11'(101036, 1949). 


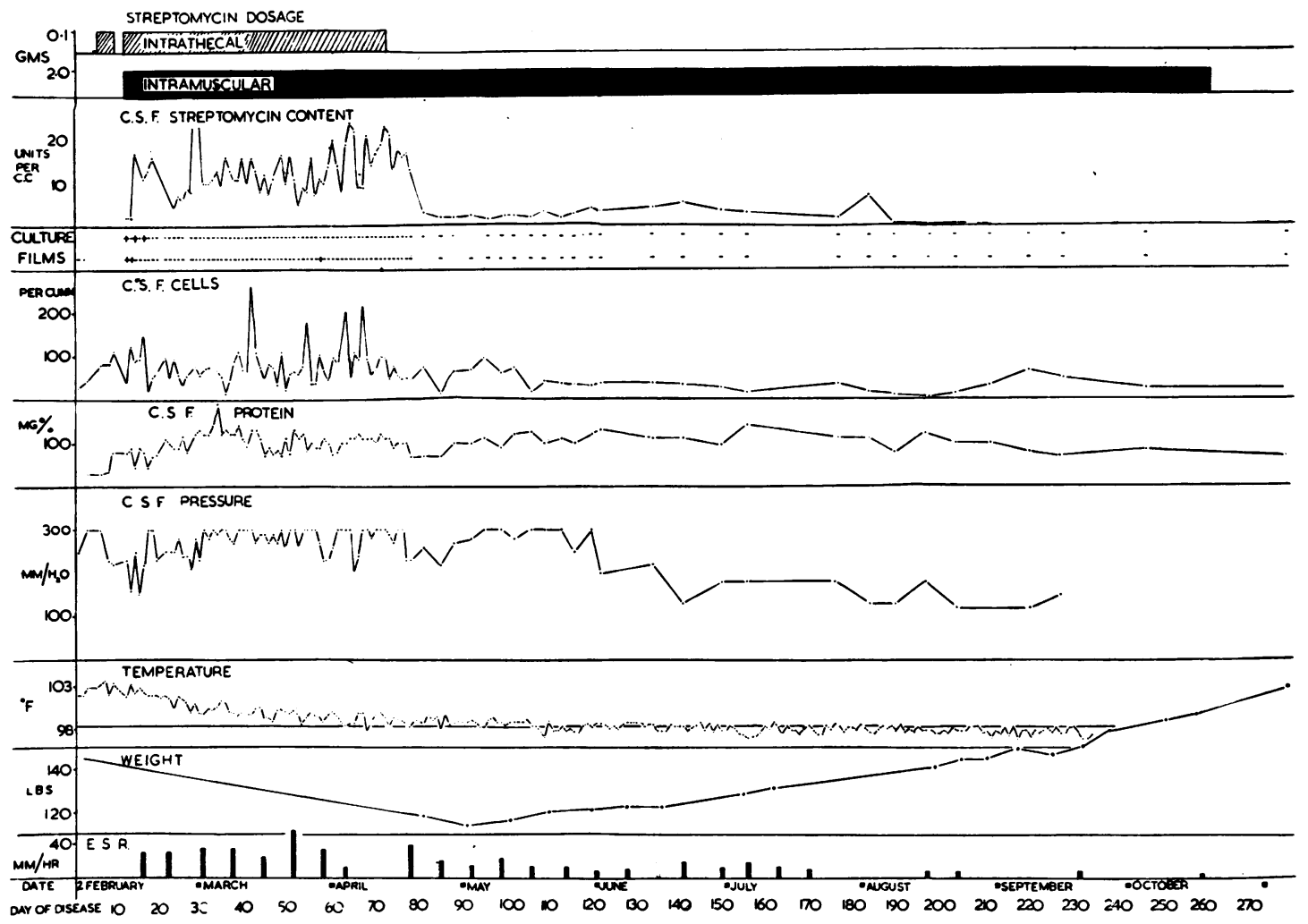

Fig. 7.-Chart showing persistently raised C.S.F. pressure during the first four months of treatment in a case of meningeal and miliary tuberculosis; eventual recovery. E.K., aged $25(83483,1948)$.

case of obstruction at the foramen of Magendie (Case 2).

The course of the intracranial pressure is no guide to prognosis. The rise encountered in the first weeks of treatment is seldom harmful and, if not excessive, may possibly do good by hindering the development of spinal block. But there are patients who are very ill on admission partly as a result of pressure-coning; in these a withdrawal of cerebrospinal fluid from the lateral ventricle may save life, but some patients still die owing to the intensity of their disease. In the case which is doing well the lumbar and ventricular pressures may become normal after one to six weeks (Fig. 4), and in children the sutures cease to spread. This improvement probably results from canalization of the exudate in the subarachnoid cisterns. It is maintained in most of the successful cases throughout the remaining months of the illness, even though the cerebrospinal fluid pathways are far from normal. The abnormality is shown by the fact that, if the patient happens to acquire a superadded pyogenic meningitis, intracranial pressure can quickly rise to excessively high levels never encountered in uncomplicated pyogenic meningitis, that is to say levels of $1,000 \mathrm{~mm}$. or more. In tuberculous meningitis it is probably many months before the subarachnoid spaces are clear of exudate; in some successful cases traces of it persist indefinitely and become calcified.

In some cases which end fatally pressure falls during treatment and may remain low until shortly before death, when there is a terminal rise (Fig. 6) which often coincides with an exacerbation of the meningeal infection. A high intracranial pressure in the third and fourth months of treatment is usually due to persistent activity of the infection rather than to inert fibrous adhesions (Fig. 7).*

In infants with enlarging heads, and adults with papilloedema and high lumbar cerebrospinal fluid pressures, attempts have been made to relieve the hydrocephalus by operative measures, which include cerebellar decompression, lateral, and

* Persistently high intracranial pressure may sometimes be in part caused by extensive chest lesions which can interfere with the return of venous blood from the cranium. 
even third, ventriculostomy, and short-circuits between the ventricular system and the subarachnoid space of the cerebral hemispheres. In our experience these operations have usually not been successful, and the best hope of relieving the communicating hydrocephalus is to persist with intrathecal and systemic streptomycin. A little improvement in the tuberculous lesions in the subarachnoid cisterns seems to suffice to relieve the rise of pressure, presumably as a result of canalization of the granulation tissue.

Not all cases of raised intracranial pressure, however, are due to communicating hydrocephalus. In our first 125 cases of tuberculous meningitis treated with streptomycin there were three cases in which there was a severe rise of intracranial pressure from lesions which were, or should have been, amenable to surgery. One patient had a tuberculous abscess of the parietal lobe, another had obstructive hydrocephalus from blockage of the foramen of Magendie, while the third had hydrocephalus of the inferior horn of one lateral ventricle from blockage of the body of the ventricle. In addition, we have seen in one patient a temporary rise of ventricular pressure during the third month of treatment which was associated with temporary arterial hypertension and papilloedema (Cairns and Taylor, 1949, Case 4). In this case the rise of intracranial pressure was successfully treated by intermittent withdrawal of cerebrospinal fluid from the lateral ventricles.

It is difficult to lay down rules about the treatment of raised intracranial pressure in tuberculous meningitis. But in general it can be said that lumbar and bilateral ventricular taps with careful manometric studies are essential in the investigation of any case of raised intracranial pressure, and that if the circumstances of the case are at all unusual ventriculography should be performed. We do not favour continuous ventricular drainage to relieve raised intracranial pressure: there is too much risk of mixed infection if it is continued for more than three to four days, and in infants it may be followed by cerebrospinal fistula; moreover, it may produce a great rise of protein with intense and widespread blocking of the spinal and cisternal subarachnoid spaces (Cairns, 1949). In most cases we have found intermittent lumbar or ventricular drainage most satisfactory. However, in severe progressive meningitis it is not indefinitely effective, and these patients may die from attacks of acute hydrocephalus even though the ventricles have been frequently tapped.

The intense hydrocephalic reactions which not infrequently follow the use of intrathecal tuberculin (P.P.D.) can be successfully controlled by this method (Smith and Vollum, 1950), and we make it a rule never to use tuberculin intrathecally without cranial burr-holes.

Intubation of the Cisterna Interpeduncularis

- In several cases we have inserted fine polythene tubes into the cisternae chiasmaticus and interpeduncularis with the object of draining off the highly proteinaceous fluid which is found in that region and of injecting streptomycin more directly to the chief site of the disease. The method proved practicable and seemed useful in early cases, but was not pursued owing to the difficulty of providing a suitable base-line from which to test its efficacy (Smith, Vollum, and Cairns, 1948; Cairns, 1949; Cairns, Smith, and Vollum, 1950).

In France streptomycin has been injected into the basal meninges through the sphenoidal fissure by means of orbital puncture (Tapie, Monnier, Garipuy, Delaude, and Bouisson, 1950).

\section{Intubation of the Subdural Space}

This method has been used in Florence in cases of communicating hydrocephalus with the idea of maintaining communication between the meninges and the ventricle, for the administration of streptomycin, and for therapeutic drainage in cases of raised intracranial pressure (Pasquinucci and Milani Comparetti, 1949; Cocchi, 1950). It is difficult to understand the rationale of this procedure, for the subdural space is not in communication with the subarachnoid pathways. It lies outside the bloodcerebrospinal fluid barrier, as has been shown by studies with penicillin (Cairns, 1947). There is no evidence that streptomycin or any other antibiotic can pass in appreciable amounts from the subdural to the subarachnoid space.

Unusual Manifestations of Tuberculous Meningitis

The following three cases, from our first 125 cases treated with streptomycin, are examples of variations in the disease which may call for the use of surgical methods in diagnosis and treatment.

Case 1. Pulmonary Tuberculosis. Tuberculous Abscess of Left Parietal Lobe. Tuberculous Meningitis. Death from Raised Intracranial Pressure. L.E., a stonemason aged 40, was admitted on August 16, 1949 (R.I. 6273/43). This man had suffered for three years from fibro-caseous pulmonary tuberculosis of both apices, with a positive sputum. One month before admission he began to have attacks of frontal headaches, of dizziness, and occasional paraesthesiae in the right hand, with difficulty in writing. He reported these symptoms at his periodic visit to the Tuberculosis Clinic and was admitted to hospital.

On examination he looked ill, and his sputum contained numerous tubercle bacilli, subsequently shown by Dr. Vollum to be normally sensitive to streptomycin. 


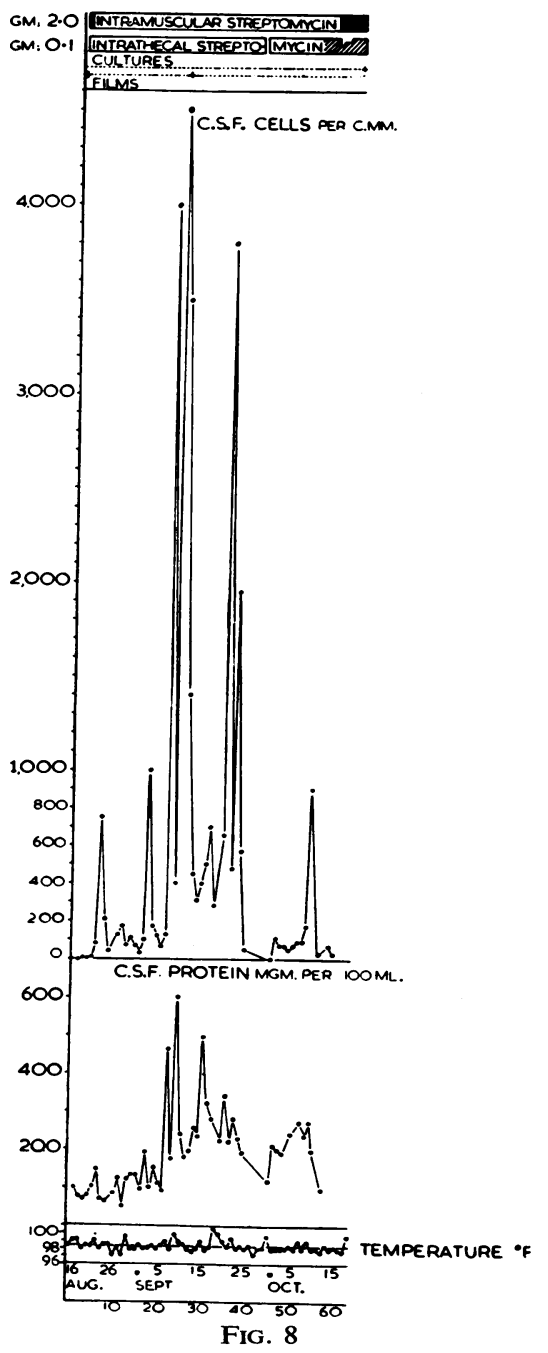

FIG. 8.-Case 1: chart showing the cellular and protein reaction of the C.S.F.

FIG. 9.-Case 1: collapsed left parietal abscess with severe oedema of the surrounding white matter, and narrowing and downward displacement of the lateral ventricle.
No neurological signs were found. Lumbar puncture yielded a clear fluid under a pressure of $200 \mathrm{~mm}$. containing no white cells and $100 \mathrm{mg}$. of protein per $100 \mathrm{ml}$.; in the films of this fluid one acid-fast bacillus was found. $\mathrm{He}$ was treated with daily injections of streptomycin both intramuscularly and intrathecally. Clinical signs of meningitis gradually appeared, and the cerebrospinal fluid showed a rising content of white cells and protein (Fig. 8). On August 22 the white cell count of the cerebrospinal fluid was 747 per c.mm. (96\% polymorphonuclears), as compared with 83 on the previous day, and cultures for pyogenic organisms were sterile. On September 7 there was a second sudden rise of white cells from the previous level of 124 per c.mm. to 4,000 per c.mm. (97\% polymorphonuclears). Two days later acid-fast bacilli, on this occasion numerous, were found in the cerebrospinal fiuid, and his headache was worse, and accompanied by vomiting. On September 20 a further burst of polymorphonuclear white cells occurred in the cerebrospinal fluid $(3,800$ per c.mm., almost all of them polymorphonuclear). His condition deteriorated, and at the end of September he was for a time dysarthric and had bilateral abducens palsy. By October 10 he was irrational and confused and exhibited a right hemiparesis and slight dysphasia.

From October 15 to 18 he had a series of generalized fits, and was found to have papilloedema. Ventricular punctures through frontal burr-holes failed to find the left lateral ventricle, though it had been found two weeks before; from the right side cerebrospinal fluid under pressure considerably above $300 \mathrm{~mm}$. was withdrawn, with temporary relief. On October 17 he fell out of bed, bruising his right temple, and next day became comatose and died, notwithstanding further ventricular taps.

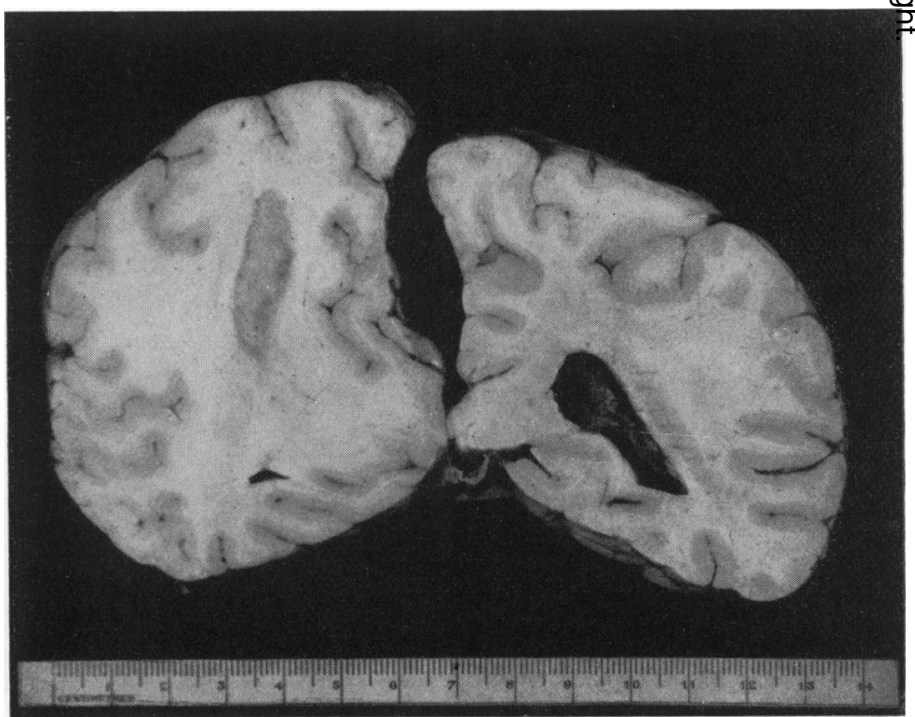

FIG. 9 
Necropsy showed a large abscess in the white matter of the left parietal lobe, with severe oedema of the surrounding white matter and herniations of the uncinate gyri and cerebellar tonsils. This abscess, which in the partly collapsed state (Fig. 9) measured $5 \mathrm{~cm}$. by $3.5 \mathrm{~cm}$. by $2 \mathrm{~cm}$., contained very numerous tubercle bacilli, mostly as intracellular clumps. There was only the slightest opacity of the basal meninges, and the spinal meninges looked normal. Each lung showed a cavity at the apex and below that caseous bronchopneumonia. There were no signs of tuberculosis elsewhere. $M$. tuberculosis was isolated from the lungs, as well as from the brain abscess, and both strains grew readily in a concentration of 500 units per $\mathrm{ml}$. of streptomycin and were more than 2,000 times as resistant as the standard strain H37 RV. Tubercle bacilli were also grown from cerebrospinal fluid from the right lateral ventricle obtained at necropsy; the resistance of these organisms was not tested.

This case mirrored one of uncomplicated meningitis until shortly before death, but in several respects it proved to be most unusual. There was a large encapsulated abscess in the left parietal lobe which was swarming with intracellular tubercle bacilli. Death was due to raised intracranial pressure, and the meningitis was exceptionally mild for a case in which tubercle bacilli had been found in the cerebrospinal fluid two months before death. At that time there were no white cells in the cerebrospinal fluid, and symptoms of meningitis and pleocytosis of the cerebrospinal fluid only appeared six days later. The cellular response in the cerebrospinal fluid consisted of intermittent bursts of polymorphonuclear cells (Fig. 8), and the appearance of tubercle bacilli in the cerebrospinal fluid seemed to be fitful: on one day very numerous acid-fast bacilli in the cerebrospinal fluid, and then no more. It was as though there were occasional leakages of pus and tubercle bacilli from the brain abscess into the meninges, and that what we were observing was the initial cellular response of the meninges to infection, similar to the initial polymorphonuclear response observed by Dr. Honor Smith and her colleagues after injection of tuberculin (P.P.D.) into the meninges of a sensitized subject (Smith and Vollum, 1950). Another feature of great interest is the development within two months of streptomycin-resistant strains of tubercle bacilli in the lungs, and the identification of similar resistant organisms in the brain abscess. In the circumstances, the mildness of the meningitis is noteworthy.

In its clinical course this case presented at the outset no very unusual features, and it was unfortunately thenceforth regarded as a case for a routine course of streptomycin intramuscularly and intrathecally. One can only conjecture what neurological signs may have been overlooked. The lesson is that all cases under treatment should be subjected to frequent clinical examination, and that when anything suggesting focal disease is found, such as the right hemiparesis and dysphasia in this case, or when a lateral ventricle cannot be found through the burr-hole, then recourse should be had to ventriculography or arteriography. In most cases no expanding lesion requiring operation will be found, but there is no other way of insuring the recognition of the unusual cases like Case 1.

Case 2. Miliary Tuberculosis. Tuberculous Meningitis. Acute Obstructive Hydrocephalus. Death. A.R., a boy aged 6, was admitted on October 19, 1949 (R.I. 113913/49). This boy fell ill in May, 1949, with miliary tuberculosis and tuberculous meningitis, and from the middle of June until October was treated with streptomycin in another hospital. After initial improvement his condition gradually deteriorated, and he was admitted to the Radcliffe Infirmary on account of hydrocephalic attacks and suspected spinal block.

He was flushed, stuporous, and emaciated, and his neck was rigid. Choroidal tubercles were present, and acid-fast bacilli were seen in two early samples of ventricular cerebrospinal fluid. His skull sutures were not separated, and there was no papilloedema, but he suffered frequent hydrocephalic attacks in which he gave a high-pitched shriek, became pale and pulseless, and stopped breathing. These attacks could be stopped by withdrawing cerebrospinal fluid from the lateral ventricle, but they recurred, and he died in one of them 10 days after admission and five months after the onset of his illness. In spite of the severe recurring clinical manifestations of raised intracranial pressure, the pressure of ventricular cerebrospinal fluid was never above $300 \mathrm{~mm}$., and it gradually fell till in the last days of life it was atmospheric.

At necropsy there was minimal meningitis (Fig. 10), but intense granular ependymitis with numerous tubercles on and in the choroid plexuses of the lateral ventricles. The foramina of Magendie and Luschka were blocked as a result of ependymitis, and there was a severe degree of hydrocephalus of the whole ventricular system, with herniation of the uncinate gyri and of the cerebellar tonsils, one of which was necrotic at its tip, an indication of intense local rise of pressure. In the lungs miliary tubercles were barely visible.

In this case the tuberculous infection was unusual in being very mild in the meninges, even in the cisterns about the mid-brain, whereas in the choroid plexuses it was intense and was associated with chronic ependymitis of the ventricular walls. Dr. Dawn Bosanquet, who has studied all our necropsy material, has never previously seen a case in which the choroid plexus was the main site of active disease in the central nervous system. Presumably the brain infection was primarily from the choroid plexus by way of the blood stream, and the resulting ependymitis led to sealing-off of the exits of the fourth ventricle. The intrathecal streptomycin, which had been given entirely by the 


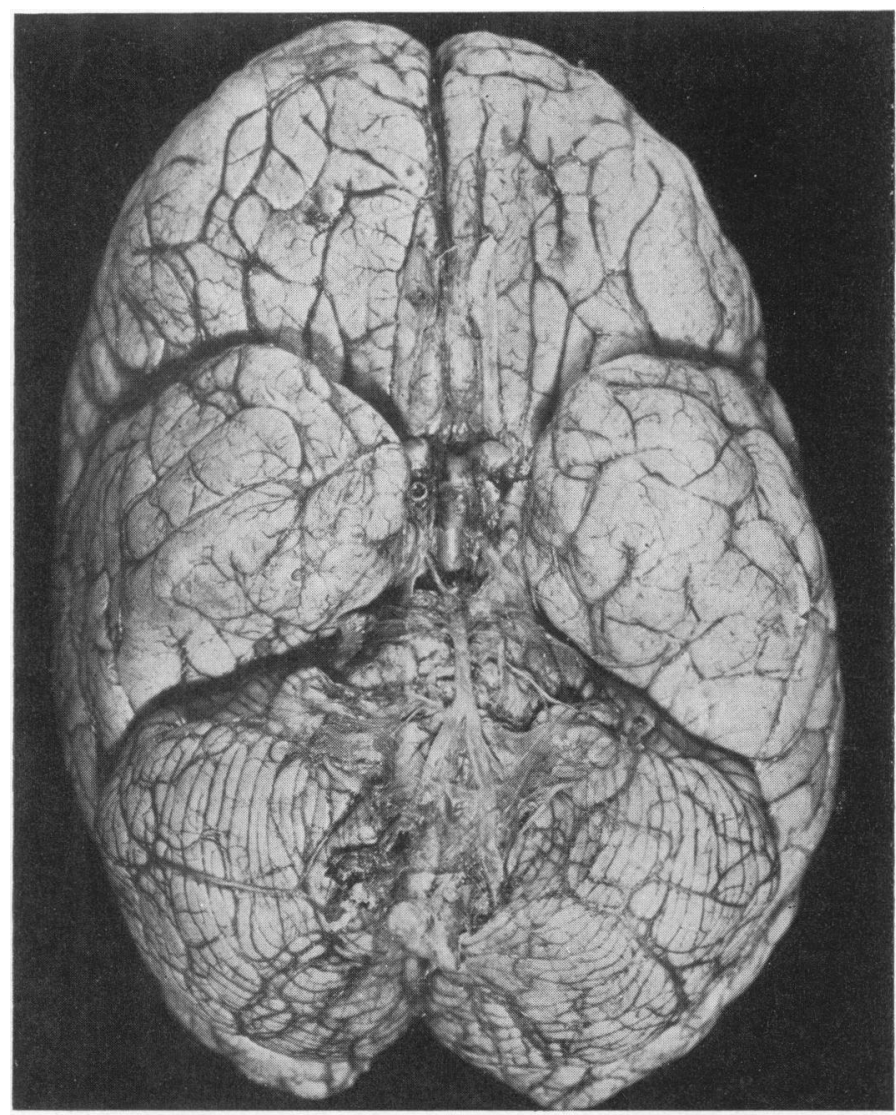

FIG. 10.-Case 2: (a) base of brain showing minimal meningitis, grooving of the uncinate gyri, and haemorrhagic necrosis of right cerebellar tonsil; (b) dilatation of the obstructed fourth ventricle with ependymitis of its wall.

FIG. $10 a$

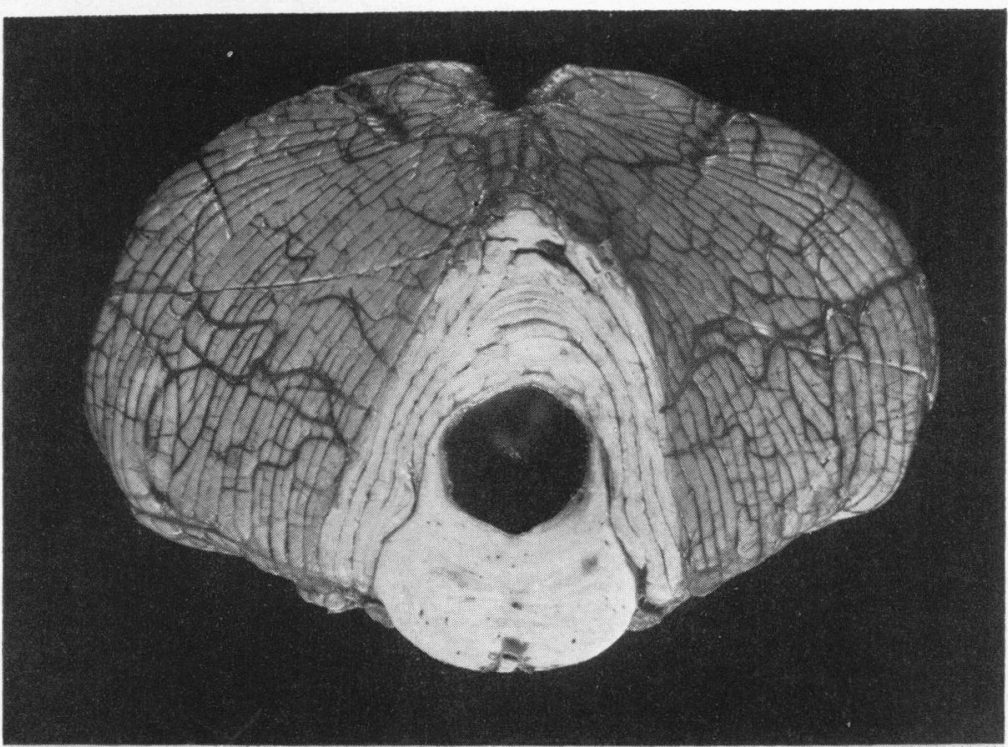

|III||

FIG. $10 b$ 
lumbar route, overcame the infection of the subarachnoid space, but did not reach the ventricles. This view is supported by the fact that Dr. Vollum cultured tubercle bacilli from 12 of 12 samples of ventricular cerebrospinal fluid and none of seven samples of lumbar cerebrospinal fluid obtained during the last 10 days of life; and the protein content of the ventricular fluid was always high, between 300 and $750 \mathrm{mg}$. \%.

The patient died from acute hydrocephalus due to obstruction of the exits of the fourth ventricle, with severe uncinate herniations compressing the mid-brain and tonsillar herniations compressing the medulla oblongata and spinal cord. And though the tuberculous infection of the ventricles was so intense as to offer little hope, yet in retrospect it seems that the one chance of a successful result lay in re-establishing an exit from the fourth ventricle by open operation and giving intensive streptomycin by the ventricular route. At the time, however, diagnosis of the precise nature of the hydrocephalus was not easy. Obstructive hydrocephalus was suspected, and eight days before death Dr. Honor Smith carried out manometric studies which gave rather equivocal results. The child was struggling and screaming, and thus it was not possible to obtain accurate pressure readings. At first the lumbar and ventricular pressures appeared to be identical at about $200 \mathrm{~mm}$. Withdrawal of fluid from the lumbar needle lowered the ventricular pressure, but it appeared to lower the lumbar pressure more markedly. The ventricular pressure was then lowered, and after withdrawal of $5 \mathrm{ml}$. the lumbar pressure had also fallen. It was concluded that there was no serious degree of ventricular or spinal block.

Simultaneous lumbar and ventricular manometric studies are clearly of doubtful value in diagnosing ventricular block, and one must therefore inject dyes, tracer-substances like penicillin, or air into the ventricles and see if they escape into the cisterna magna and spinal subarachnoid space. Each of these methods has some disadvantages. In the urgent case of suspected 'obstructive' hydrocephalus air injection is probably the most certain method, but fairly large amounts of air $(50 \mathrm{ml}$. or more) must be injected, and it should be realized that if the obstruction is proved immediate operation must follow; otherwise the reaction to the air injection is dangerous to life.

Attention must also be called to the co-existence of acute and fatal hydrocephalic attacks with low pressure in the lateral ventricles. This combination is not uncommon in established hydrocephalus. Pressure within the cranium is not uniform in all the dural compartments and, once the tentorial opening has become obstructed by uncinate or vermis herniation, withdrawal of fluid from the lateral ventricles may fail to lower the pressure in the posterior fossa (Cairns, 1939).

Case 3. Tuberculous Meningitis, Development of Localized Hydrocephalus of Right Lateral Ventricle in the fourth month of Illness. Operation: Ventriculo-cisternostomy. Recovery. T.B., a boy aged 3 years, was admitted on November 26, 1950 (R.I. 134091/50). This child developed tuberculous meningitis in August, 1950, the primary focus and the source of infection remaining undetermined. The meningeal infection was confirmed bacteriologically and was treated with streptomycin intramuscularly and intrathecally at Northampton General Hospital. He did well until the 95th day of his illness when he became sleepy and feverish, vomited, and developed a meningeal cry, with slowing of his pulse from 120 to 72 . He was then transferred to the Radcliffe Infirmary.

On admission the child was drowsy and apathetic. There was nystagmus in all directions, slight weakness of the left external rectus, and an obvious left hemiparesis. The cerebrospinal fluid showed no change from the previous findings, and this was thought to exclude a mixed pyogenic infection and, probably, recrudescence of the tuberculous meningeal infection. Three days after admission the child suddenly screamed, his face suffused, he lost consciousness, and his left upper limb was strongly extended; his pulse rate dropped to 40 , and his respirations to eight per minute. Bifrontal burr-holes were immediately made: the right anterior horn could not be found; the left was displaced to the left and contained cerebrospinal fluid under a pressure of $270 \mathrm{~mm}$. Withdrawal of cerebrospinal fluid was followed by improvement in the child's condition.

On the same day percutaneous carotid angiography showed signs of an avascular space-occupying lesion in the right temporal lobe (Fig. 11). It was thought that this might be a tuberculoma, and on the evening of the same day (November 29, 1950) Mr. Pennybacker explored the temporal lobe by means of an osteoplastic flap. The lobe was greatly swollen, and this was found to be due, not to a tuberculoma, but to a grossly dilated inferior horn of the lateral ventricle. A subtemporal decompression was performed. At this operation needle biopsies of brain tissue showed traces of a fungus mycelium, and samples of cerebrospinal fluid from the dilated inferior horn yielded on culture fungus spores which were later identified as aspergillus. Similar spores were isolated from the lumbar and ventricular cerebrospinal fluid for the next five days and then disappeared.

After a stormy course for a week after operation he began to improve, and it became evident that he had a left homonymous hemianopia, and sensory loss as well as weakness in his left limbs. In January, 1951, he became irritable and increasingly lethargic, and his subtemporal decompression became tense. A second angiogram showed increasing arterial displacement from the right temporal lesion (Fig. 11). On February 1 air was injected into the inferior horn of the right lateral ventricle, and the radiographs showed that it was grossly dilated and not connected with the rest of the 


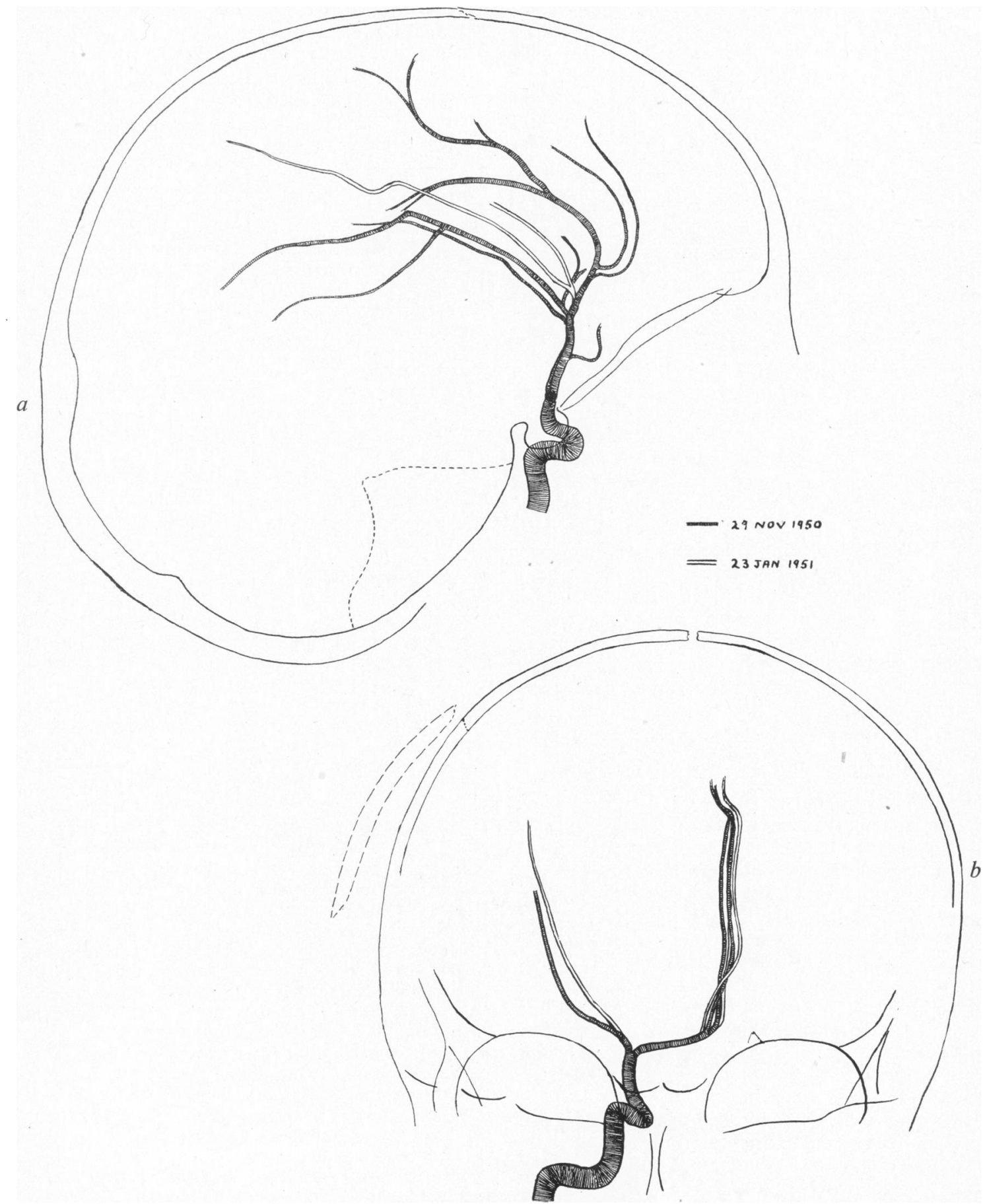

FIG. 11.-Case 3: superimposed angiographic tracings at intervals of eight weeks. (a) Lateral, showing progressive upward displacement of middle cerebral artery; $(b)$ antero-posterior, showing progressive displacement to the left of the anterior and middle cerebral arteries. 

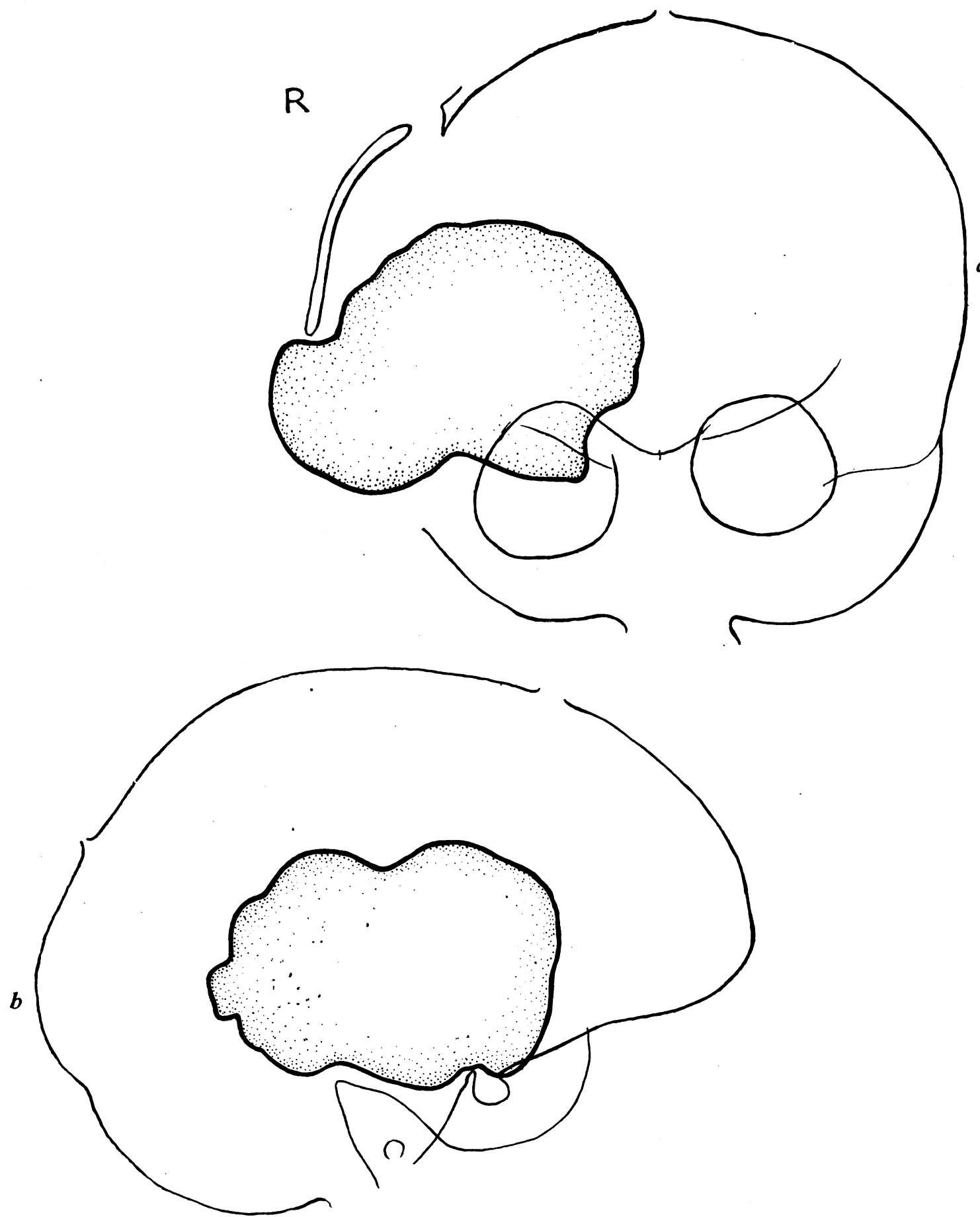

FIG. 12.-Case 3: tracings of air injections showing hugely dilated inferior horn of the right lateral ventricle, not communicating with the rest of the ventricular system: $(a)$ antero-posterior; (b) lateral. 
ventricular system (Fig. 12). On the same day the posterior fossa was explored, and a polythene tube was passed from the dilated right inferior horn into the cisterna magna, which looked normal (ventriculocisternostomy). Spores of aspergillus were once more found in the cerebrospinal fluid of the dilated inferior horn.

After this operation the patient immediately became much brighter and more active, happier and more cooperative. His left hemiparesis improved dramatically in the course of four days and the sensory signs also disappeared; the left homonymous hemianopia resolved into an upper quadrantic defect. The white cells and protein in the cerebrospinal fluid gradually subsided, and streptomycin was stopped, though not before he had become severely deaf. Six months later the child was well but still ataxic.

Localized hydrocephalus of one part of the lateral ventricle was first encountered following missile wounds involving the body of the lateral ventricle (Cairns, Daniel, Johnson, and Northcroft, 1947). In these cases a septum formed across the body of the ventricle which isolated the inferior horn from the anterior part of the ventricle, with the result that cerebrospinal fluid formed by the choroid plexus of the inferior horn could not escape from the sealed portion, and the inferior horn became an expanding cyst. A similar condition may be encountered after ventricular haemorrhage from birth injury, and we have also seen it following a brain abscess of the paraventricular white matter of the parietal lobe.

In the present case of a proved but mild tuberculous meningitis the aetiology of the local hydrocephalus is obscure. It seems unlikely that tuberculous ependymitis could produce such a septum in a previously normal ventricle, though it probably could render a pre-existing ventricular stenosis from birth injury complete. Another possibility to be considered is the aspergillus infection of the cerebrospinal fluid and of the brain; but this, which may have been a contamination during intrathecal streptomycin treatment, was not associated with a cellular or protein reaction in the cerebrospinal fluid and may therefore have been non-pathogenic. A third possibility is that the septum was caused by a tuberculoma in the choroid plexus of the lateral ventricle or in the paraventricular white matter; this is rendered unlikely by the fact that the ventricular infection was mild: the protein content of the hydrocephalic cyst was only $25 \mathrm{mg}$. \%, and the white cells were 24 per c.mm.

\section{Summary}

Frontal burr-holes for tapping the lateral ventricles have proved to be necessary in about one-third of our cases of tuberculous meningitis treated with streptomycin. Apart from this minor operation, neurosurgical procedures are not called for in most cases. However, there is the occasional case (three in our first 125) in which a major operation to deal with some unusual cause of raised intracranial pressure is essential to save life. In retrospect, when we can see the whole course of the cerebrospinal fluid reaction and the results of bacteriological cultures, and can correlate these with the clinical events, it is not difficult to perceive that these cases are unusual. But at the time they can closely resemble the usual type of tuberculous meningitis, and it is all too easy to overlook the urgent need for special neurosurgical investigations and treatment.

It is clearly of the greatest importance that during streptomycin treatment each case should be frequently re-assessed by thorough neurological examination and study of the cerebrospinal fluid charts; and that ventriculography or cerebral angiography should be undertaken if the headaches are unusually severe, if there are signs of disturbed function of a cerebral hemisphere, or if the case is taking an unusual course under treatment.

\section{REFERENCES}

Cairns, H. (1939). Brit. J. Surg., 27, 275.

(1947). Brain, 70, 251.

(1949). Brit. med. J., 1, 969.

- Daniel, P., Johnson, R. T., and Northcroft, G. B. (1947). Brit. J. Surg., War Surg. Suppl. No. 1, p. 187.

155.

—- Smith, H. V., and Vollum, R. L. (1950). J. Amer. med. Ass., 144, 92.

Carrea, R. (1951). Personal communication.

Cocchi, C. (1950). Sci. med. Ital., 1, 7.

Goodhart, J. F., and Still, G. F. (1913). ' The Diseases of Children,' 10th ed., p. 607 . London.

Lorber, J. (1951). Archives of Disease in Childhood, 26, 33 .

Pasquinucci, G., and Milani Comparetti, A. (1949). Riv. Clin. pediat., 47, 77.

Smith, H. V., and Vollum, R. L. (1950). Lancet, 2, 275.

-, , and Cairns, H. (1948). Ibid., 1, 627.

Tapie, J., Monnier, J., Garipuy, J., Delaude, A., and Bouisson, H. (1950). Bull. Soc. méd. Hôp. Paris, 66, 698. 